\title{
Recuperação escolar: uma análise crítica a partir da Psicologia Escolar
}

\author{
Roseli Fernandes Lins Caldas \\ Universidade Presbiteriana Mackenzie, SP \\ Marilene Proença Rebello de Souza \\ Universidade de São Paulo, SP
}

\begin{abstract}
Resumo
O artigo retrata o recorte de um estudo sobre a recuperação escolar fundamentado na abordagem histórico-cultural, cujos objetivos foram: a) estabelecer uma análise crítica, a partir dos conceitos da psicologia escolar sobre programas de recuperação na educação pública paulista; e b) compreender os sentidos pessoais atribuídos à recuperação escolar por educadores, mães e alunos. De cunho qualitativo, essa pesquisa etnográfica utilizou-se dos seguintes procedimentos: observações participantes; entrevistas com gestores, professores, alunos e mães; e desenhos dos alunos. Os resultados revelaram grande distanciamento entre as propostas oficiais e sua concretização no cotidiano escolar. A busca do sentido da recuperação conduziu à conclusão de que essa prática configura-se muito mais como um espaço de impossibilidades do que de potencialidades. As classes de recuperação exercem em alunos e professores o pernicioso efeito de cristalização do "não saber" - professores destituídos de sua função de ensinar e alunos desistentes de suas possibilidades de aprender.
\end{abstract}

Palavras-chave: Psicologia Escolar, políticas públicas, educação básica.

\section{Summer school: a critical analisis based on School Psychology.}

\begin{abstract}
This article describes a part of a study on Summer School, based on the Cultural-Historical Psychology theory that has the purpose to: a) establish a critical analysis, applying the concepts of school psychology about Summer School programs on the public system of São Paulo; and b) understand the personal sensations of educators, mothers and students regarding Summer School. This ethnographic research, which has a qualitative characteristic, used the following procedures: participative observations; individual interviews with coordinators, teachers, students and mothers; and student's drawings. The results demonstrated a huge distance between the official proposals and its achievement in the daily routine inside the school. The search for a meaning for the Summer School has taken us to conclude that such method represents more a space of impossibility than a place to potentialities. The Summer School classes cause a negative effect of the "not knowing" crystallization, resulting in teachers who are dismissed from their roles to teach, and students who give up on their possibilities to learn.
\end{abstract}

Key words: School Psychology, public policies, elementary school.

\section{Recuperación escolar: un análisis crítico a partir de la Psicología Escolar}

\section{Resumen}

El artículo describe un estudio sobre la recuperación escolar fundamentado en el enfoque histórico-cultural cuyos objetivos fueron: a) establecer un análisis crítico a partir de conceptos de la psicología escolar sobre programas de recuperación en la educación pública paulista; y b) comprender el sentido personal asignado a la recuperación escolar por educadores, madres y alumnos. La investigación etnográfica de carácter cualitativo utilizó los siguientes procedimientos: observaciones participantes; entrevistas con gestores, profesores, alumnos y madres; y dibujos de alumnos. Los resultados mostraron diferencias significativas entre las propuestas oficiales y su aplicación concreta en el cotidiano escolar. Buscar el sentido de la recuperación condujo a la conclusión de que esta práctica se configura mucho más como un espacio de imposibilidades que de potencialidades. Las salas de recuperación causan en alumnos y profesores el efecto pernicioso de cristalización del "no saber" - profesores destituidos de su función de enseñar y alumnos desertores de sus posibilidades de aprender.

Palabras Clave: Psicología Escolar, políticas públicas, educación básica. 


\section{Introdução}

O interesse da Psicologia Escolar pelas políticas públicas tem se intensificado no Brasil a partir das discussões produzidas na década de 1980, quando vários trabalhos científicos realizados por psicólogos passaram a tratar especificamente das políticas educacionais, algumas de âmbito nacional e outras implantadas em São Paulo - SP.

É indispensável vislumbrar as políticas públicas em educação como assunto que também diz respeito à Psicologia Escolar, considerando-se os efeitos da materialização dos planos e metas oficiais na constituição das pessoas, atores sociais da escola com os quais a Psicologia tem estreito compromisso. Assim, pouco a pouco vai se consolidando o imperativo de que política pública em educação seja assunto discutido na interlocução entre as searas da Educação e da Psicologia Escolar. Cabe destacar que no caso não se trata de qualquer concepção de Psicologia Escolar, mas da que compreende o homem como constituído nas mais variadas relações sociais, culturais e históricas, muitas delas fortemente marcadas pelas vivências na instituição escolar - afinal, é nesse espaço em que as políticas educacionais se concretizam e de fato acontecem, que nos cabe, como psicólogos, identificar e denunciar o "hiato entre a intenção e a realidade" (Souza, 2006, p. 232 e 235).

O tema das políticas públicas tem grande importância como permanente pano de fundo para a recuperação escolar, uma vez que várias políticas são elaboradas, pressupondo a necessidade de classes de recuperação para atender alunos que não tenham conseguido adequar-se aos objetivos propostos.

Nas últimas décadas a Psicologia Escolar brasileira tem discutido possibilidades de superar a alienação, e muitos autores têm encontrado na vertente da Psicologia Histórico-Cultural meios para preencher as lacunas deixadas pelas discussões sobre o fracasso escolar. Tomando emprestada a concepção de educação proposta por Saviani de que "o trabalho educativo é o ato de produzir, em cada indivíduo singular, a humanidade que é produzida histórica e coletivamente pelo conjunto de homens" (Saviani, 2005, p.24), a pesquisa cujo recorte é aqui descrito elegeu a Psicologia Histórico-Cultural como base teórica do caminho a ser trilhado em busca de respostas às indagações sobre a recuperação escolar.

O estudo teve como objetivo desvelar, compreender e revelar os atravessamentos gerados pela prática pedagógica da recuperação escolar, na tentativa de "entender e denunciar mecanismos sutis de exclusão" encobertos pela promessa de apoio e auxílio aos que não aprendem, bem como propor caminhos para superar contradições presentes na recuperação escolar, com vista a contribuir para uma reflexão sobre a escola enquanto instrumento de emancipação para todos os alunos, inclusive os destinados às classes de recuperação.

Este artigo é um recorte da tese de doutorado defendida em 2010 no Instituto de Psicologia da USP denominada Recuperação escolar: discurso oficial e cotidiano educacio- nal - um estudo a partir da Psicologia Escolar. Tal estudo teve como principais objetivos efetuar uma análise crítica da recuperação escolar praticada na educação pública paulista ao longo da história e compreender quais as interpretações e os sentidos pessoais atribuídos no cotidiano escolar à recuperação pelos envolvidos, especialmente pela equipe técnica, pelos professores, pais e alunos de uma escola pública paulista.

Para ir além das críticas às maneiras como esta proposta se efetiva e das críticas às estratégias utilizadas, torna-se imprescindível fortalecer críticas aos pressupostos de uma prática que há muito se põe como compensatória às dificuldades das crianças de famílias de baixa renda. Ao se tomar tal medida, independentemente do modo como se materialize, entende-se que as dificuldades pertencem aos alunos que precisam ser recuperados. Deste modo, não se trata de verificar quais os melhores caminhos para atingir os objetivos previstos nos projetos oficiais de recuperação, mas de questionar tais objetivos.

\section{Contribuições da Teoria Histórico-Cultural para a compreensão do fenômeno da recuperação escolar}

A escolha da perspectiva da Psicologia Histórico-Cultural para fundamentar a pesquisa deveu-se à compreensão de ser este o referencial teórico mais apropriado para um estudo que pretendia investigar a singularidade de pessoas envolvidas em processos de recuperação escolar a partir das categorias Sentido e Significado, considerando-se que os pressupostos construídos por essa teoria possibilitam entrelaçar a história das pessoas envolvidas no processo de recuperação com a história dessa prática pedagógica ao longo do tempo, levando em conta os contextos culturais que permeiam o cotidiano escolar observado. Outro elemento essencial à pesquisa descrita neste artigo o qual encontra sustentação nessa teoria diz respeito ao valor das relações que se estabelecem na escola - tanto entre as pessoas como entre estas e o conhecimento - para o desenvolvimento psíquico, ou seja, a investigação sobre a função da sala de aula - nesse caso, da sala de recuperação - como espaço de formação social da mente.

Essa concepção pressupõe "mecanismos pelos quais a cultura torna-se parte da natureza de cada pessoa" (Vigotski, 2007, p. 83), de modo que o homem é compreendido como alguém que se constitui em uma relação dialética entre o social e a história, sendo ao mesmo tempo único, singular e histórico, um ser que, ao nascer, é candidato à humanidade, mas somente dela se apropria no processo de apropriação do mundo (Aguiar, 2006).

Dentre as inúmeras contribuições dos autores precursores da Teoria Histórico-Cultural, os conceitos de sentido e significado explicitados por Vigotski e de Leontiev e destacados a seguir são fundamentais para a discussão do sentido da recuperação escolar. 
Para Vigotski (1935), o significado, inseparável da palavra, é o princípio organizador do desenvolvimento da consciência, voltado a determinado conceito compartilhado pelo grupo social. O sentido, por outro lado, é a integração dos eventos psicológicos despertados por determinada palavra na consciência de cada pessoa, uma vez que o efeito provocado em uma criança por qualquer acontecimento ou situação dependerá do sentido que ela lhe imprima.

Assim, o homem, ao nascer, encontra um sistema de significações pronto, elaborado historicamente, e toma posse dele; mas o modo como este homem se apropria ou não, e em que grau assimila ou não determinada significação, ou o efeito que este significado tem em sua personalidade, dependem do sentido pessoal atribuído por ele.

Asbahr (2005) esclarece com bastante precisão estes conceitos:

A passagem do mundo social ao mundo psíquico não se dá de maneira direta, o mundo psíquico não é cópia passiva do mundo social, isto é, as significações sociais compartilhadas por meio da linguagem não são apropriadas imediatamente pelos homens. Essa apropriação depende do sentido pessoal atribuído às significações sociais. Dessa forma, a relação entre significação social e sentido pessoal é componente central da consciência humana (Asbahr, 2005, p. 15).

Para Leontiev (1981), o sentido individual se dá quando a criança toma consciência de dado fenômeno para além do conhecimento a respeito deste. Sentido pode ser entendido como o conjunto dos fenômenos psíquicos suscitados na consciência por um fenômeno, uma palavra ou uma relação. Uma vez que o sentido traduz a relação entre o motivo e a ação, para encontrar o sentido pessoal devemos descobrir o motivo que lhe corresponde.

O êxito do processo de resolução de tarefas não é determinado somente pelo conteúdo objetivo, mas depende primordialmente do motivo que impele a criança a atuar; em outras palavras, depende do sentido da atividade que realiza. $\mathrm{Na}$ particularidade dos motivos determinados pelo sentido que tenha a tarefa dada, temos o ponto essencial para análise.

As relações entre sentido e significado se expressam como relações reais da própria atividade do homem, portanto sua análise pode se constituir como um método fundamental da investigação psíquica da consciência.

Como a aprendizagem requer motivação e só há atividade verdadeira se houver motivação, para ocorrer aprendizagem é preciso que se estabeleçam vínculos afetivos capazes de conduzir a atenção dos processos intelectuais aos objetos de conhecimento. Desse modo, trata-se de pensar um processo pedagógico que seja "motivador porque faz sentido para o aluno, como uma resposta para sua necessidade de compreender melhor sua vida e a vida em sua sociedade" (Tanamachi \& Meira, 2003, p. 50).

Pode-se deduzir que o sentido pessoal da criança em relação às experiências vividas na escola está ligado às particularidades psicológicas da sua atividade na escola produzidas tanto por suas interações com o professor, com o trabalho e com os seus colegas de classe quanto pela maneira de perceber a matéria escolar, compreender as explicações e a maneira como organiza sua linguagem nas respostas ao professor, etc. O modo como esses diversos processos afetam sua vida psíquica imprimirá o sentido pessoal ao processo de escolarização.

\section{A pesquisa}

A busca por compreender o espaço destinado à recuperação escolar, considerando-se que "nos bastidores de uma política pública gesta-se uma direção a ser dada àqueles que a ela se submetem" (Souza, 2006, p. 234), aguçou dúvidas a respeito das perspectivas e concepções de educação presentes nos bastidores da recuperação escolar e dos efeitos que recaem sobre os seus protagonistas. Além disso, o questionamento sobre as contribuições da Psicologia Escolar no sentido de consolidar ou superar tais concepções foi fundamental para provocar desconforto e inquietação, condições indispensáveis para a realização de qualquer investigação científica.

As contribuições da Psicologia Escolar são inegáveis, pois esta descortina um novo modo de estudar o fracasso escolar, buscando referenciais teórico-metodológicos que possibilitem uma compreensão mais fiel à sua complexidade. As concepções - que ora entendiam a educação como a principal responsável pelas transformações sociais, ora como simples reprodutora das distorções da estrutura social - deram lugar a outra compreensão de educação, tida como determinada social e economicamente, mas com certo grau de autonomia que a tornava um caminho de grande valia na busca de uma sociedade mais justa. A década de 1980 tornou-se o marco do início de uma produção científica que busca as contradições de medidas e reformas educacionais feitas pelos órgãos oficiais com a utilização de inovações metodológicas, como a pesquisa-ação ou a pesquisa participante, possibilitando "análises das condições objetivas de vida e de trabalho, das representações, ações, reações e relações dos participantes do processo escolar" (Patto, 1988, p. 77).

Ter como fonte de informação o ambiente em que ocorre o fenômeno investigado, descrever detalhadamente os dados, manter o interesse no processo e não nos resultados ou produtos, a investigação indutiva - que é construída à medida que as informações vão se agrupando -, a preocupação com o sentido que as diferentes pessoas dão às suas vidas e às suas vivências são os principais aspectos que caracterizam a pesquisa qualitativa, e foram devidamente respeitados no presente estudo.

$\mathrm{Na}$ investigação, utilizando-nos de fundamentos da pesquisa qualitativa, procuramos estabelecer estratégias e procedimentos que permitissem um diálogo com os participantes a partir da convivência e aproximação, buscando-se levar em conta as experiências relativas às classes de recuperação do ponto de vista dos protagonistas da escola 
(Bogdan \& Biklen, 1994). Somente assim é possível testemunhar os fenômenos escolares: quando chegamos perto das pessoas que deles participam e passamos algum tempo convivendo e partilhando suas experiências à luz do referencial teórico construído pela Psicologia Escolar.

Surgida como uma opção radicalmente diversa dos paradigmas dominantes na pesquisa educacional, a etnografia implica em observação e interpretação das realidades a serem estudadas a partir das concepções teóricas assumidas pelo pesquisador, portanto é consequência do trabalho teórico, e não a matéria-prima que Ihe dá origem.

Mais do que uma técnica ou opção metodológica, a etnografia indica um enfoque, uma perspectiva em pesquisa que se articula com um método e uma teoria e se distingue pelo respeito à natureza do que é estudado. O objeto de estudo se constrói teoricamente, vinculando-se os conceitos construídos às referências empíricas vividas em campo (Rockwell, 1987). O etnógrafo carrega as discussões teóricas em suas perguntas e nas tarefas de observação e interpretação do campo a ser pesquisado.

Assim, buscou-se primeiramente investigar como se constituíram as classes de recuperação ao longo da história e, depois, compreender como os protagonistas de uma escola específica apropriam-se desses espaços escolares tidos como recuperadores de aprendizagem.

\section{Método}

No presente estudo foi utilizada a observação participante, especificidade da pesquisa etnográfica apropriada da antropologia e aplicada às pesquisas educacionais que tem como uma de suas maiores expressões o trabalho desenvolvido por Ezpeleta e Rockwell (1986).

De caráter qualitativo, o estudo utilizou-se das seguintes fontes de informação: a) documentos oficiais sobre recuperação, teses e dissertações publicadas, documentos produzidos pela rede oficial de ensino e registros escolares; b) observações participantes nas salas de recuperação, durante alguns meses do semestre letivo; c) entrevistas individuais com professoras de classes de recuperação, gestores e mães de alunos de classes de recuperação; d) entrevistas coletivas com um grupo de alunos dessas classes; e) desenhos feitos por eles sobre a classe de recuperação, sendo todos vinculados regularmente a uma escola estadual situada na Zona Sul da cidade de São Paulo.

O presente texto deter-se-á basicamente na análise das informações obtidas na pesquisa de campo a partir das observações participantes e entrevistas.

\section{Participantes}

Como elementos complementares às observações etnográficas em campo, foram realizadas entrevistas semidirigidas individuais com as duas professoras de classes de recuperação, a diretora da escola, a professora coordenado- ra pedagógica e duas mães de alunos; e entrevistas coletivas com dois grupos de alunos das classes de recuperação, todos vinculados à mesma escola da rede pública, situada na Zona Sul da cidade de São Paulo.

\section{Procedimentos}

Foram realizadas dezessete visitas à escola, nas quais o pesquisador permanecia em sala de aula durante as aulas de recuperação fazendo semanalmente observações e interagindo com alunos e professoras, tanto durante quanto após as aulas.

A observação era estruturada para registro posterior, de modo a selecionar as cenas e diálogos que diziam respeito aos objetivos da pesquisa, a qual era caracterizada como participante, uma vez que havia constantes interações com alunos e professoras, procurando-se vivenciar e entender o sistema de referências deles. No tempo em que estivemos na escola procuramos fazer parte daquele grupo, tentando o máximo de convivência e integração com alunos e professoras. Pudemos perceber a aceitação gradual das professoras em relação à presença da pesquisadora em sala de aula. No início houve certa resistência, mas pouco a pouco fomos nos aproximando e estabelecendo vínculos que nos comprometiam umas com as outras na busca de respostas às questões que se apresentavam.

As aulas de recuperação tinham a duração de uma hora e ocorriam após o período regular de aulas dos alunos, tanto no turno da manhã como no da tarde.

Os roteiros utilizados em cada uma das entrevistas foram complementados e enriquecidos diferentemente, em função dos depoimentos específicos de cada participante, surgindo, assim, nas entrevistas, outros assuntos além dos que inicialmente faziam parte dos roteiros.

Todas as entrevistas tiveram a autorização dos participantes ou responsáveis, por meio da assinatura do Termo de Consentimento Livre e Esclarecido, para serem realizadas e gravadas de modo a registrar as próprias palavras dos sujeitos, sendo, posteriormente, transcritas para as devidas análises.

Os resultados das investigações foram organizados articulando-se a análise da realidade em estudo e a teoria produzida sobre o tema, por se entender ser este o melhor caminho para possibilitar a interpretação da realidade.

Três foram as rotas para a organização das informações obtidas na pesquisa de campo: relatos registrados no diário de campo, elaborados a partir das observações feitas nas salas de recuperação; relatos orais coletados a partir de entrevistas (alunos, professoras, mães, diretora da escola e professora coordenadora pedagógica); e desenhos feitos pelos alunos sobre as classes de recuperação.

Para entrecruzar as informações obtidas por meio das diferentes fontes da pesquisa, foi utilizada a organização/ categorização proposta por Bogdan e Biklen (1994, p. 220), a qual sugere a análise da compreensão dos participantes da pesquisa sob os seguintes prismas: (1) da situação - no 
caso, a classe de recuperação; (2) de si próprios em relação à situação; e (3) uns dos outros.

As informações obtidas tanto nas entrevistas como por meio das observações no campo foram organizadas em uma tabela para cada categoria de participantes, considerando-se os eixos indicados: a) compreensão sobre a recuperação; b) compreensão sobre os outros participantes do processo de recuperação; c) compreensão de cada uma sobre si mesma.

Buscando encontrar elementos que permitissem esboçar o sentido atribuído às classes de recuperação pelos que as vivenciavam, valemo-nos de procedimentos de análise de investigações baseados no esforço de ultrapassar a aparência (os significados) e ir à busca dos sentidos construídos pelos eventos psicológicos no plano das motivações, necessidades e interesses.

\section{Resultados e análise}

As falas dos participantes da pesquisa, tanto as que foram ouvidas durante as observações participantes como aquelas que resultaram das entrevistas, constituíram-se no ponto de partida em busca dos significados e sentidos constituídos.

Importante frisar que as categorias significado $e$ sentido, embora diferentes, não podem ser compreendidas desvinculadas uma da outra, e para sua compreensão devem ser considerados os processos cognitivos, afetivos e biológicos que as constituem.

A análise das palavras implica, necessariamente, na análise dos pensamentos, e esta pressupõe a compreensão dos motivos, necessidades e interesses que orientam as atividades humanas. Isso evidencia a grande complexidade desse processo, em que registros permeados de emoções, baseados em desejos e em tensões mobilizadoras dos sujeitos, criam experiências afetivas em relação às suas ações.

Segundo Aguiar (2006), "esse processo de ação do sujeito no mundo a partir das suas necessidades só vai se completar quando o sujeito significar algo do mundo social como possível de satisfazer suas necessidades" (p. 17). Somente então o objeto/fato/pessoa poderá ser vivido como algo que motiva o sujeito.

Tentando dar voz aos participantes, destacamos aqui algumas de suas falas, consideradas emblemáticas:

"Chamo José e não sei ler. Eu me esforço, mas já fiz reforço quatro vezes. Na $1^{a}$, na $2^{a}$, na $3^{a}$ e na $4^{a}$. Todo ano faço reforço... Eu sou o pior, já até repeti um ano."- aluno de 11 anos, da classe de recuperação.

"É um vazio, eu me sinto vazia, apesar da supervisora ter acompanhado eles neste semestre e achar que eles avançaram. As professoras também disseram que eles avançaram um pouco. Eu penso naqueles que não avançaram nada. Me dá um vazio porque eu queria que todos tivessem alfabéticos." - professora da classe de recuperação.

"Vira uma tortura. Soa como um castigo. Acaba perdendo o ritmo, tanto o professor como o aluno e a escola acabam só cumprindo uma formalidade. Faz porque tem que fazer (...). Sinceramente, desanimei. Sabia como fazer, vem alguém que me manda fazer de um jeito que sei que não dá certo, é pra desanimar mesmo. É pra não funcionar, mesmo. Pra inglês ver." - diretora da escola.

Aparentemente, os objetivos da recuperação foram sofrendo alterações com o passar do tempo; mas como as concepções a respeito dos alunos tidos como os "que não aprendem", dos educadores e da função da escola têm se mantido intactas em suas bases, a mudança de foco da recuperação ao longo das diferentes legislações não traz efeitos reais ao processo de aprendizagem, especialmente dos alunos considerados "com dificuldades", aos a recuperação sempre se destinou.

Embora os discursos das professoras e gestoras participantes dessa pesquisa tenham apontado como ideal a recuperação contínua, ou seja, o processo de apoio dado diariamente em classe pela própria professora à recuperação paralela - feita em separado para os alunos com dificuldades -, ainda continua sendo conferido um poder mágico de salvar os que não aprendem. Ainda é evidenciada a necessidade de segregar os que aprendem de modo diferente, com outros ritmos que os distingam da maioria dos alunos. A recuperação põe-se como medida para solucionar as dificuldades encontradas pelos alunos em seu processo de aprendizagem, mas como sua concretização na escola aponta muito mais para a discriminação e rotulação do que para a superação dos obstáculos, é possível afirmar que a recuperação escolar vem sendo instrumento de mascaramento da realidade e, consequentemente, de alienação.

Sustentamos essa ideia por considerarmos, concordando com Duarte (2006), que uma das formas mais evidentes de alienação é aquela que provoca o impedimento da apropriação das riquezas do gênero humano, entre as quais, em nossa sociedade letrada, a aprendizagem da leitura e escrita. Dito de outro modo, sempre que alguém não consegue aprender a ler e a escrever na escola, sempre que o direito à aprendizagem não se concretiza na vida dos indivíduos, há, implicitamente, um processo de impedimento de sua humanização.

Um breve tempo de convivência na escola, durante a pesquisa de campo deste trabalho, bastou para ouvirmos nos corredores a reedição da voz de D'Ávilla, autor do primeiro documento oficial sobre recuperação escolar na rede paulista, datado de 1939, confirmando um sistema que insiste em pregar a recuperação como "salvadora das crianças fadadas ao fracasso escolar, com o objetivo de reajustá-las ao ambiente da classe (...), estimulando-lhes as forças, corrigindo-Ihes as deficiências, reforçando-Ihes a capacidade de aprender" (D’Avilla, 1959, p. 15). 
A partir dessas considerações, destacamos a seguir alguns aspectos comuns, referentes às relações com a recuperação escolar, que surgiram com mais frequência nos encontros com os participantes desta pesquisa, considerando-se as respostas nas entrevistas e as vivências no campo.

Cabe realçar a presença constante dos problemas físicos ou psicológicos como elementos explicativos das dificuldades de aprendizagem na concepção de todos os participantes desta pesquisa. Nas entrevistas tanto das duas professoras como da coordenadora, da diretora, das mães e dos próprios alunos, havia constantes referências a doenças físicas ou emocionais como justificativas para a não aprendizagem, o que implicava no pertencimento à classe de recuperação.

A mesma concepção que fundamentou a proposta documentada por D'Ávilla na década de 1950 se faz presente nos discursos dos participantes da pesquisa. Sua descrição dos alunos que necessitavam da recuperação naquela época indicava características ainda hoje atribuídas aos alunos matriculados nas classes de recuperação; ou seja, a concepção sobre os alunos de recuperação, guardadas as diferenças na terminologia, ainda se mantém inalterada nos discursos proferidos na escola mais de 60 anos depois: "Tardos na aprendizagem; deficientes por desvios disciplinares ou fraqueza mental; repetentes; instáveis; apáticos; imaturos; e prejudicados pelo próprio meio social, familiar" (D’Ávilla, 1959, p. 2).

Merecem destaque também as várias menções dos educadores e mães às possibilidades de dislexia, TDH ou problemas neurológicos como hipóteses explicativas das dificuldades dos alunos das classes de recuperação.

Maria Aparecida Moysés e Cecília de Azevedo Collares, entre outros pesquisadores, têm trazido grandes contribuições para a desmistificação da relação entre questões escolares e os supostos distúrbios, denunciando o processo de medicalização da Educação, perigoso engano que transforma em doença fisiológica o que essas autoras denominam de "complexo de doença social" (Moysés \& Collares, 1993).

Desde os seus primórdios a recuperação é tida como "remédio ao grave problema da repetência". A preferência de D'Ávilla pelo termo remédio parece conter pressupostos ainda hoje bastante sugestivos.

O mito de Sísifo ${ }^{1}$ ilustra com perfeição os relatos de gestoras, de professoras, de mães e dos próprios alunos sobre sua relação com o trabalho desenvolvido na escola, em especial nas classes de recuperação. Algumas vezes pode-se verificar na escola como que certo conformismo de todos os envolvidos: alunos tentando fugir das aulas de recuperação, professores indagando "o que se há de fazer...", gestores apenas cumprindo determinações nas quais não acreditam.

1 O mito de Sísifo é um ensaio filosófico escrito por Albert Camus, publicado originariamente em 1942. Por ter enganado e ofendido a Zeus, por toda a eternidade Sísifo foi condenado a rolar uma grande pedra de mármore com suas mãos até o cume de uma montanha, sendo que toda vez que ele estava quase alcançando o topo a pedra rolava novamente montanha abaixo até o ponto de partida por meio de uma força irresistível. Por esse motivo, a tarefa que envolve esforços inúteis passou a ser chamada "Trabalho de Sísifo".
A frase dita por uma das professoras é ilustrativa desse fenômeno de acomodação: "É muito difícil, mas, como diz que nada é impossível, a gente vai trabalhando". O processo de recuperação escolar revelou um efeito esmagador para os envolvidos. Sofrimento e sentimentos negativos em relação às atividades exercidas na escola foram relatados por alunos, professoras, coordenadora pedagógica, diretora e mães.

O "não saber", a incompetência, aparece nas falas de todos os participantes, professoras, professora coordenadora pedagógica, diretora, mães e alunos. Todos se revelaram destituídos de potencialidades e possibilidades, passando, assim, a potencializar outros como responsáveis por eventuais mudanças. A busca por resposta na área da saúde, especificamente na da medicina, pode ter aí sua explicação.

Outro ponto que merece discussão é o fato de que a razão principal pela qual os alunos são encaminhados para a classe de recuperação são as insuficiências no processo de leitura e escrita, cabendo destacar o pensamento de Vigotski a este respeito, que pode fomentar novas alternativas à recuperação escolar. Esse autor enfatiza a importância de que a mediação no processo de ensino da leitura e escrita se dê não de modo mecânico, mas de modo vivo e significativo. Importante lembrar que, por serem estas as atividades principais nesse momento do desenvolvimento infantil, saber ler e escrever está diretamente relacionado às concepções que a criança tem de si mesma. Suas vivências na escola em relação à aprendizagem são generalizadas para a vida e interferem diretamente em seu desenvolvimento psíquico.

Vigotski afirma em seus estudos:

El niño de edad escolar generaliza los sentimientos, es decir, cuando una situación se ha repetido muchas veces nace una formación afectiva que tiene la misma relación con la vivencia aislada o el afecto, que el concepto con la percepción aislada o el recuerdo. (...) Justamente en la crisis de los siete anos es cuando surge la propia valoración, el niño juzga sus éxitos, su propia posición. (Vigotski, 2006, p. 380)

O sentido da recuperação é impregnado dos efeitos das experiências escolares permeadas de fracassos e não de êxitos, e isso se aplica não somente aos alunos, mas a cada um dos atores sociais da escola participantes desta pesquisa.

\section{CONSIDERAÇÕES FINAIS - uma proposta alternativa à recuperação escolar}

A teoria de Vigotski convida a vislumbrar potenciais, a olhar para frente e deter-se nas potencialidades de aprender que tem a criança, em contraposição a um olhar que procura somente o que lhe faltou, onde precisaria ter se desenvolvido mais ou como poderia ter aprendido melhor. Recuperar implica em olhar para o passado - verificar o que a criança não 
conseguiu aprender -, ao passo que ensinar, de acordo com a Psicologia Histórico-Cultural, necessariamente nos remete ao futuro - ao que ela é capaz de aprender. Para Vigotski, "a pedagogia deve orientar-se não no ontem, mas no amanhã do desenvolvimento da criança" (Vigotski, 2001, p. 333).

É óbvio que a concepção de falta evidencia-se no processo de aprendizagem de um aluno de nove ou dez anos que ainda não está alfabetizado, a despeito de estar na escola desde os sete anos; porém cabe questionar a origem dessa falta. Estaria no aluno ou nas circunstâncias em que se dá o processo de aprendizagem? Segundo Meira e Antunes (2003), quando o foco está nas circunstâncias, a chance de mudança é muito maior do que quando se centra nas pessoas.

Deste modo, dois eixos podem guiar o enfoque das faltas: em primeiro lugar, as faltas não pertencem à criança ou à professora, mas são multideterminadas e ampliam-se para diversas instâncias, entre as quais as políticas públicas; e, em segundo lugar, é preciso pensar a defasagem do processo de aprendizagem sob a ótica dos potenciais dos envolvidos no processo (as faltas até podem ser vislumbradas, desde que sirvam de indicadores de possibilidades).

Em relação aos alunos marcados pelo fracasso escolar, a função da escola deveria ser, de modo mais intenso ainda, a de possibilitar, por meio do ensino de conhecimentos sistematizados, o desenvolvimento deste nível de pensamento abstrato e mais elaborado, caracterizado pela formação de conceitos científicos. A educação escolar tem ao seu encargo a responsabilidade de promover o desenvolvimento de conceitos científicos cada vez mais aprofundados, de forma a provocar alterações qualitativas na consciência dos alunos. Não obstante, evidenciam-se as incoerências entre as propostas na regulamentação oficial das classes de recuperação enquanto espaços de apropriação do conhecimento e o que de fato ocorre: crianças com tarefas simplificadas, repetitivas, com conteúdos muito aquém do que é ensinado nas salas regulares, atrasadas no cronograma curricular oferecido aos demais, desacreditadas, segregadas em um espaço destinado a quem, supostamente, não consegue aprender e com investimentos pedagógicos incipientes: uma escola mais fácil, uma escola fraca para os fracos.

Vigotski (2005) argumenta que "a criança atrasada, abandonada a si mesma, não pode atingir nenhuma forma evolucionada de pensamento abstrato" (Vigotski, 2005, p. 113), e, exatamente por isso, a escola tem tarefa primordial em seu desenvolvimento.

Este trabalho dispôs-se a ser mais uma voz que se junta a tantas outras da Psicologia Escolar que criticam as políticas públicas e medidas educacionais segregadoras e manifestam resistências a medidas que desqualificam a escola como espaço de socialização do saber, objetivo historicamente produzido, propondo o enfrentamento da exclusão social, mascarada e ocultada pela realidade concreta da recuperação escolar.

Nesse sentido, terminamos o artigo indicando como proposta alternativa a valorização da prática de aproveitamento dos pares mais hábeis em sala de aula, de modo que o auxílio mútuo entre alunos que se encontrem no nível real em relação a algum processo de aprendizagem e outros que estejam na zona do desenvolvimento proximal possa se concretizar como medida pedagógica oficial, contrapondo-se aos espaços reservados à recuperação e maximizando as potencialidades de cada criança.

Isso implicaria em abolir o termo recuperação, uma vez que o caminho seria a ênfase nas potencialidades por meio de processos de aprendizagem tendo-se como sustentação teórica para essa proposta a argumentação de Vigotski sobre as possibilidades de assessorar as crianças deficientes de modo a produzir avanços em seu desenvolvimento e propor sua aplicação aos alunos tidos como atrasados na escola, entendendo-se o atraso na aprendizagem como um processo a ser superado. A sala de aula deve ser um espaço emancipador, e a escola só é emancipadora quando revela o que as pessoas são, não o que não são. Para definir superação pode-se recorrer à palavra na língua alemã aufheben, que significa esconder, ser posto em segundo plano.

Assim, a deficiência não é eliminada, mas é escondida pelas potencialidades, é submetida às novas possibilidades que vão sendo desenvolvidas (Vigotski, 1997). É como se o brilho das potencialidades das crianças tornasse opacas suas impossibilidades.

Os processos compensatórios foram propostos por Vigotski (1997) em sua teoria da Defectologia, relativa ao desenvolvimento de crianças com atraso mental.

Aventuramo-nos a propor sua aplicabilidade ao estudo dos alunos tidos como atrasados em seu processo de escolarização, comumente alvos do encaminhamento às classes de recuperação. É preciso deixar bem claro que não há qualquer intenção de sugerir que haja atraso mental ou de ordem biológica nos alunos das classes de recuperação; ao contrário, a aproximação desses alunos, por meio da pesquisa de campo, deu-nos certeza de estarmos diante de crianças inteligentes e com muito potencial para aprendizagem, o qual, de algum modo, foi usurpado delas no processo de escolarização.

Os atrasos desses alunos são outros, de ordem escolar, que não devem ser entendidos como próprios deles, mas como atrasos socialmente construídos. As dificuldades que apresentam no processo de escolarização na sala de aula regular são o seu passaporte para as classes de recuperação, cujo objetivo oficial é prover as necessidades educacionais, o que, na realidade, resulta em cristalização de atrasos. Vigotski elaborou uma crítica aos critérios de seleção das crianças encaminhadas para as classes específicas para deficientes. Eram escolhidas pelo critério de capacidade ou incapacidade ou - o que era pior - pelo fato de serem tidos como alunos que não desejavam aprenderfator muito recorrente na concepção dos alunos encaminhados às classes de recuperação. Para esse autor russo, não havia nada mais infundado do que uma seleção segundo ângulos negativos, ou seja, uma seleção apoiada somente naquilo que falta à criança, e não naquilo que ela é e tem e, especialmente, no que ela pode vir a conquistar em termos de desenvolvimento. Entendia que o estudo da deficiência só fazia sentido se propiciasse a superação das dificulda- 
des dessas crianças tidas como mentalmente atrasadas. As questões que deveriam nortear os procedimentos dos educadores seriam: quais os processos do desenvolvimento que podem levar à superação do atraso, elevando essa criança a um nível superior? Quais as suas potencialidades? Como fazê-la desejar aprender?

Para inteirar-se dessa questão é preciso estudar não somente a defasagem, mas principalmente o lugar que esta insuficiência ocupa na personalidade e as reestruturações que se processam nessa criança, bem como as condições sociais e o meio em que ela é educada, uma vez que:

la reserva de la compensación es en una enorme medida, la vida social colectiva del niño, la sociabilidad de su conducta, en las cuales encuentra el material para construir las funciones internas que se originam en el processo del desarrollo compensatório (Vigotski, 1997, p. 137).

Se as crianças com deficiências podem desenvolver processos de adaptação ao meio, elaborando uma série de funções que compensam, equilibram e suplantam as deficiências, pode-se inferir a importância da escola para as crianças tidas como portadoras de fracasso escolar e, no caso deste estudo, pertencentes às turmas de recuperação. As reservas de compensação, sobretudo para crianças de classes populares, serão construídas nos processos de aprendizagem proporcionados dentro do espaço da sala de aula regular. Este olhar que vislumbra potenciais, capacidades, habilidades nas crianças deve ser o prisma adotado pelos educadores, gestores e pais.

As considerações de Vigotski a respeito do objetivo da Psicologia diante das crianças com dificuldades para aprender nos conduzem a um grande desafio, enquanto psicólogos voltados à área da Educação: lutar por uma escola pública que seja comprometida com a mediação cultural e que contribua, de fato, para a emancipação.

Nossa busca pela recuperação conduziu à conclusão de que o espaço reservado à recuperação escolar configura-se muito mais como um lugar de impossibilidades do que de potencialidades. A recuperação não tem o efeito alardeado oficialmente, mas tem outros efeitos.

As classes de recuperação exercem em alunos e professores o pernicioso efeito de cristalização do "não saber": professores destituídos de sua função de ensinar e alunos desistentes de sua possibilidade de aprender.

Foi consensual, entre os diferentes personagens da escola, a concepção sobre a fragilidade da função da recuperação, apontando o esvaziamento do sentido dessa prática pedagógica para todos os seus atores: gestores, professores, alunos e pais.

Encerramos com o desejo de que este trabalho tenha mais um sentido luta por uma educação de qualidade na escola pública brasileira e seja um anúncio da possibilidade de que a recuperação propagada pelos discursos oficiais como solução dê lugar a outro processo que nos aventuramos a denominar de "Aprendizagem Contínua".
Neste sentido, é preciso que a Psicologia Escolar continue denunciando políticas públicas que não contribuem para a concretização de uma escola pública de qualidade. Assim, é preciso comemorar conquistas, sem perder de vista que ainda há muito por fazer para que a educação seja, de fato, promotora de dignidade humana para todas as crianças brasileiras!

\section{Referências}

Aguiar, W. M. J. (2006). A pesquisa junto a professores: fundamentos teóricos e metodológicos. Em W. M. J. Aguiar (Org.), Sentidos e significados do professor na perspectiva sócio-histórica. (pp. 5-22). São Paulo: Casa do Psicólogo.

Asbahr, F. S. F. (2005) O sentido pessoal e projeto político pedagógico: análise da atividade pedagógica a partir da psicologia histórico-cultural. Dissertação de Mestrado, Instituto de Psicologia, Universidade de São Paulo, São Paulo.

Bogdan, R., \& Biklen, S. (1994). Investigação Qualitativa em Educação: Uma introdução à teoria e aos métodos. Portugal: Porto Editora.

D'Ávilla, A. (1959). O problema da repetência e as classes de recuperação. Em IV Congresso Nacional de Professores Primários. Recife, Pernambuco.

Duarte, N. (2006). Vigotski e o aprender a aprender - crítica às apropriações neoliberais e pós-modernas da teoria vigotskiana (4a ed.). Campinas, SP: Autores Associados.

Ezpeleta, J., \& Rockwell, E. (1986). Pesquisa participante. Rio de Janeiro: Paz e Terra.

Leontiev, A. (1981). Actividad conciencia personalidad. Playa, Ciudad de La Habana: Editorial Pueblo e Educación.

Meira, M. E. M., \& Antunes, M. A. M. (2003). Psicologia Escolar: Teorias Críticas. São Paulo: Casa do Psicólogo.

Moysés, M. A. A., \& Collares, C. A. L. (1993). Sobre alguns preconceitos no cotidiano escolar. Idéias, 19, 9-25.

Patto, M. H. S. (1988). O fracasso escolar como objeto de estudo: anotações sobre as características de um discurso. Caderno de Pesquisa - Fundação Carlos Chagas, 65, 72-77.

Rockwell, E. (1987). Reflexiones sobre el processo etnográfico. (1982-1985) Investigaciones Educativas. México: Centro de Investigación y de Estudios Avançados, IPN.

Saviani, D. (2005). Escola e Democracia (38a ed.). Campinas, SP: Autores associados. 
Souza, M. P. R. (2006). Políticas públicas e educação: problemas e possibilidades. Em L. S. Viégas \& C. B. Angelucci (Orgs.), Políticas Públicas em Educação - Uma análise crítica a partir da Psicologia (pp. 229-243). São Paulo: Casa do Psicólogo.

Tanamachi, E., \& Meira, M. E. M. (2003). A atuação do Psicólogo como expressão do pensamento crítico em psicologia e educação. Em M. E. M. Meira \& M. A. M. Antunes (Org.), Psicologia Escolar: Práticas Críticas (pp. 11-62). São Paulo: Casa do Psicólogo.

Vigotski, L. S. (1935). El problema del entorno. Em: Fundamentos de la podologia - $4^{a}$ conferência publicada em Vigotski, Lev Semionovich. Leningrad: Izdanie Instituto.

Vigotski, L. S. (1997). La infância dificil. Em L. S. Vigotski, Obras escogidas: fundamentos da defectologia (Tomo V, J. G. Blanck Trad.). Madrid: Visor Dist. S.A.
Vigotski, L. S. (2001). A construção do pensamento e da linguagem. São Paulo: Martins Fontes.

Vigotski, L. S. (2006). La crise de los siete anos. Em L. S. Vigotski, Obras escogidas (Vol. IV). Madri: A. Machado Libros.

Vigotski, L. S. (2005). Aprendizagem e desenvolvimento intelectual na idade escolar. Em L. S. Vigotski, A. R. Luria \& A. Leontiev, Linguagem, desenvolvimento e aprendizagem (pp. 103-117). São Paulo: Ícone.

Vigotski, L. S. (2007). A formação social da mente (7a ed.). São Paulo: Martins Fontes.
Recebido em: 10/01/2012

Reformulado em: 26/07/2012

Aprovado em: 30/08/2012

\section{Sobre as autoras}

Roseli Fernandes Lins Caldas (roseli.caldas@uol.com.br)

Universidade Presbiteriana Mackenzie - Doutora em Psicologia Escolar e do Desenvolvimento Humano

Marilene Proença Rebello de Souza (mprdsouz@usp.br)

Livre Docente Universidade de São Paulo 